\title{
Knowledge, Awareness and Willingness to use HIV Pre-Exposure Prophylaxis (PrEP) Among Students at the University of Namibia
}

\author{
Frieda Magano Nakathingo ${ }^{1}$, Daniel Opotamutale Ashipala ${ }^{1} \&$ Petrus Tweuthigilwa Iiyambo ${ }^{2}$ \\ ${ }^{1}$ Department of General Nursing Science, School of Nursing, Faculty of Health Sciences, University of Namibia \\ (UNAM), Rundu, Namibia \\ ${ }^{2}$ Department of Statistics and Population Studies, Faculty of Science, University of Namibia, Windhoek, Namibia \\ Correspondence: Mr Daniel Opotamutale Ashipala, Department of General Nursing Science, School of Nursing, \\ Faculty of Health Sciences, University of Namibia (UNAM), PO Box 88, Kaisosi Road, Rundu, Namibia.
}

Received: November 1, 2020 Accepted: December 21, 2020 Online Published: January 25, 2021

doi:10.5539/gjhs.v13n3p48 URL: https://doi.org/10.5539/gjhs.v13n3p48

\begin{abstract}
Adequate knowledge, awareness and willingness to use HIV Pre-Exposure Prophylaxis (PrEP) is very important for HIV prevention mostly in developing countries where the burden of HIV infection continues to increase. The purpose of this study was to ascertain the level of knowledge, awareness, willingness to use HIV PrEP among tertiary students at the University of Namibia (UNAM), Rundu Campus. A quantitative, descriptive, cross-sectional design was used with a total of 232 first-year students across all three faculties at UNAM, Rundu Campus being selected using stratified random sampling. The study results showed that the majority $(52 \%$ of the participants were female and $72 \%$ of the participants were aged between 18 and 24 years. It was also found that $45 \%$ of the participants reported that they had heard of PrEP and, of this number $(n=104), 88 \%$ reported that they were willing to use PrEP, although $8 \%$ only of the respondents had actually used it. Of the respondents who reported that they had heard of PrEP, both gender and the faculty at which they were studying were significantly associated (all p-values were less than 0.05) with their awareness and knowledge of, and willingness to use, PrEP. The study findings indicated a low level of awareness, knowledge and use of HIV PrEP among the respondents, although the degree of willingness to use PrEP was high among them.
\end{abstract}

Keywords: knowlegde, willingness, use, expousure, prophylaxis, Human Immune Deficiency Virus

\section{Introduction}

HIV remains one of the global public health concerns of the world (Namhindo et al., 2018). In an effort to address this, HIV PrEP, which refers to the use of antiretroviral drugs taken prior to HIV exposure by people who are not infected with HIV in order to block or prevent the acquisition of HIV (Bekker et al., 2016). It was recently approved in Namibia (UNAIDS, 2018). PrEP is taken once daily and is dispensed as a single pill (MoHSS, 2017). Tobias (2018) further added that PrEP may be taken only during specific periods of high risk and not for an individual's entire life.

The World Health Organisation has found that HIV PrEP is 92\% to 100\% effective in preventing HIV infection (WHO, 2017). It is usually prescribed to supplement other HIV preventive tools, including condoms, lubricants, STI (sexually transmitted infection) testing and treatment, as well as regular HIV counseling and testing (The Society for Family Health Namibia, 2016). HIV PrEP is offered in various health facilities throughout Namibia with the cost being covered either by various health insurance plans or by various medication assistance programmes which provide it for free or at lower cost to enable people with limited income or no insurance to afford it (CDC, 2018). Despite the fact that HIV PrEP prevents HIV, it does not prevent other sexually transmitted diseases and it only reaches maximum protection after 20 days of use if taken every day (The Society for Family Health Namibia, 2016). There are numerous criteria which need to be met if an individual is to qualify for HIV PrEP. These include any HIV negative people with sexual partners who are HIV positive with a viral load higher than 40 copies/ml, all HIV negative people in mixed status relationships where one partner is infected with HIV and the other one is not, regardless of viral load of the partner who wants to conceive, the HIV status of the partners is unknown, recent or frequent STIs, multiple or concurrent sexual partners, the partner has a history of not using condoms on a regular basis, frequent PrEP users and a history of sexual intercourse while under the influence of alcohol or recreational drugs (PrEp watch, 2019). It is essential that protective precautions such as abstaining from 
sex or using condoms are adhered to during the first 20 days of daily dosing because it takes HIV PrEP up to 20 days to reach its maximum protection in blood, 7days in rectal tissues and 20 days in vaginal tissues (Tobias, 2018). In addition, the medication should be continued for 28 days after the last potential HIV exposure in those wishing to stop taking it (MoHSS, 2017). People taking HIV PrEP may experience some minor side effects such as nausea while, in rare cases, HIV PrEP may have an effect on bone mineral density and kidney functioning (Bak, Van Dam \& Jansse, 2019).

Young adults are the group mostly at risk for HIV infection because they make up the largest percentage of new HIV infections and are most likely to die from HIV-related causes. This leads to a massive loss in terms of the health and the economy of the country concerned (Ajayi, Adeniyi, \& Akpan, 2018). There are certain factors that have been found to be major drivers of HIV in Namibia, namely, multiple and concurrent sexual partners, intergenerational sex and unprotected sexual intercourse (Ahouada et al., 2020). Additionally, (Ahouda et al, 2020) reported that alcohol abuse, lack of protection during sex and high population mobility are other factors that contribute to the high incidence of HIV in Namibia. Namibia aims to end AIDS by 2030 by reducing the number of new infections and ensuring a decline in the number of HIV-related deaths (MoHSS, 2017).

Despite the many measures which are in place to fight the spread of HIV, young adults in Namibia continue to be disproportionately at risk of acquiring HIV (IntraHealth, 2019). The national HIV prevalence rate is $13 \%$ among people between 15 and 49 years (PEPFAR Media Information Session, 2017). This is despite the granting of approval to provide HIV PrEP following an increase in the prevalence of HIV in Namibia (MoHSS, 2017). One study in Nigeria has shown a limited level of awareness of PrEP among young adults, despite the fact that they are most at risk of contracting HIV (Ajayi, Adeniyi, \& Akpan, 2018). However, there appears to be a lack of literature on knowledge and awareness of, and willingness to use, PrEP among tertiary students at UNAM. If this information is not available, HIV infection may continue to rise daily in Namibia, despite the free availability of HIV PrEP (UNAIDS, 2018).

Students in universities are typically population groups in their twenties. Owing to a number of physical, psychological and socioeconomic attributes of adolescence (Yi, Te, Pengpid, \& Peltzer, 2018). This population group is particularly known to indulge in risky sexual behaviours, including sex with multiple partners, unprotected sex, sexual intercourse with strangers and sexual intercourse while under the influence of alcohol (PrEP watch, 2019). However, HIV PrEP could contribute to a decrease in new infections although, if people lack knowledge and awareness of, and willingness to use, HIV PrEP, they will not make use of it, particularly as HIV PrEP is relatively new in Namibia. An assessment of people's knowledge and awareness of, and willingness to use, HIV PrEP may help understand what needs to be done to facilitate HIV PrEP uptake as a preventative strategy.

\section{Methods}

\subsection{Setting}

The study was conducted in Namibia at one of the satellite campuses of the University of Namibia, located in Kavango East Region (Rundu Campus) in all first years from all three faculties namely: Faculty of Health Sciences, Faculty of Economics and Management Sciences and Faculty of Education. The University of Namibia is a premier institution of higher learning that has 12 satellite campuses nationwide.

\subsection{Study Design and Population}

A quantitative cross-sectional descriptive survey among 253 first year students across all three faculties at the University of Namibia, Rundu campus was conducted. A descriptive design was used to allow the researcher to gather as much information as possible about knowledge, awareness, willingness and the use of PrEP among tertiary students at the University of Namibia. The participants were first year students across the three faculties who are enrolled in the full time study mode at the University of Namibia, Rundu campus. The first year students were more likely to engage in explorative sexual behaviors at the time of data collection because many of them were experiencing freedom from parental guidance for the first time in adult lives.

\subsection{Data Collection}

Data were collected in September 2019 following a formal permission that was granted by the University of Namibia ethical committee. Class representatives arranged for opportunities to meet with each of their classes. Students were asked to participate in the study after the purpose of the study was explained to them. The researcher used the class register for each of the class as the sampling frame. The respondents were selected by randomly choosing the required number from the class population based on the class register. Participants were allowed to fill the questionnaires on their free will and they returned them immediately. The students' awareness of PrEP was assessed using four items in the questionnaire. The questions were mainly multiple-choice questions with the 
following options: 'Yes', 'No', and 'I do not know'. All the respondents were requested to answer the questions on their awareness of HIV PrEP.

\subsection{Statistical Analysis}

The results of descriptive analysis were presented in Tables 3.2, 3.3 and 3.4 below. In addition, the results of the Chi-Square tests (see Table 3.5) that were conducted to determine whether there was a significant association between the outcome variables, namely, the knowledge, awareness and willingness of the UNAM students to use the HIV PrEP services, and the explanatory variables such as the gender, faculty, age, year of study and religious background of the participants. The Chi-Square results determined which of the proposed explanatory variables in the study explained the variation in the outcome variables. The data was analysed using Statistical Package for Social Science (SPSS), version 24.

\subsection{Ethical Approval}

This study was conducted with approval by the University of Namibia ethical committee (SoNEC 08/2019) and Ministry of Health and Social Services (MoHSS) research unit (FMN, 2019). The researchers' conduct was guided by the following ethical principles: beneficence, non-malfeasance, confidentiality, privacy, anonymity, justice, informed consent, and autonomy. As a result, the researchers were compelled to adhere to these eight principles. Additionally, participants were assured of their right to terminate from the study at any point without having to explain themselves or receive penalties for doing so.

\section{Results}

A total number of 232 questionnaires were completed and returned which represents a $92 \%$ response rate.

\subsection{Frequency Distribution of the Social-Demographic Characteristics of the Respondents}

Table 3.1. Socio-demographic characteristics of the respondents $(n=232)$

\begin{tabular}{|c|c|c|c|}
\hline Characteristic & Outcome & $\begin{array}{l}\text { Number of } \\
\text { respondents }\end{array}$ & Percentage \\
\hline \multirow[t]{2}{*}{ Gender } & Male & 111 & 48 \\
\hline & Female & 121 & 52 \\
\hline \multirow[t]{4}{*}{ Age (years) } & $18-24$ & 179 & 77 \\
\hline & $25-29$ & 35 & 15 \\
\hline & $30-34$ & 15 & 7 \\
\hline & 35 and older & 3 & 1 \\
\hline \multirow[t]{3}{*}{ Faculty } & School of Nursing & 32 & 14 \\
\hline & Education & 130 & 56 \\
\hline & Economics and Management Sciences & 70 & 30 \\
\hline \multirow[t]{4}{*}{ Marital status } & Single & 220 & 95 \\
\hline & Married & 6 & 3 \\
\hline & Divorced & 3 & 1 \\
\hline & Widowed & 3 & 1 \\
\hline \multirow[t]{3}{*}{ Religious background } & Christian & 221 & 96 \\
\hline & Muslim & 8 & 3 \\
\hline & Other (Ancestor worship, Hindus, etc) & 2 & 1 \\
\hline
\end{tabular}

\subsection{Frequency Distribution of Respondents by Awareness and Knowledge of, and Willingness to Use, PrEP}

The distribution of the responses regarding their awareness and knowledge of, and willingness to use, HIV PrEP is presented in Tables 3.2, 3.3 and 3.4 respectively

Table 3.2 presents the frequency distribution of the respondents in terms of various characteristics of their 
awareness of HIV PrEP.

Table 3.2. Awareness of HIV PrEP

\begin{tabular}{|c|c|c|c|}
\hline Characteristic & Outcome & $\begin{array}{l}\text { Number } \\
\text { respondents }\end{array}$ & Percentage \\
\hline \multirow[t]{3}{*}{ Ever heard of PrEP? } & Yes & 104 & 45 \\
\hline & No & 125 & 54 \\
\hline & Non-response & 3 & 1 \\
\hline \multirow[t]{6}{*}{ Source (s) of information regarding PrEP } & Friend/relative & 34 & 15 \\
\hline & Health facility & 45 & 19 \\
\hline & Radio and/or television & 16 & 7 \\
\hline & Internet & 6 & 3 \\
\hline & $\begin{array}{l}\text { Others (written source, more than one } \\
\text { source, etc) }\end{array}$ & 30 & 13 \\
\hline & Non-response & 101 & 44 \\
\hline \multirow[t]{3}{*}{$\begin{array}{l}\text { Do you know where to access PrEP } \\
\text { services? }\end{array}$} & Yes & 96 & 41 \\
\hline & No & 132 & 57 \\
\hline & Non-response & 4 & 2 \\
\hline \multirow[t]{4}{*}{$\begin{array}{l}\text { Is PrEP given free of charge in state health } \\
\text { facilities? }\end{array}$} & Yes & 80 & 35 \\
\hline & No & 11 & 5 \\
\hline & I do not know & 135 & 58 \\
\hline & Non-response & 6 & 3 \\
\hline
\end{tabular}

Table 3.3 presents the frequency distribution of respondents according to various characteristics pertaining to their knowledge of HIV PrEP.

Table 3.3. Knowledge of HIV PrEP

\begin{tabular}{llll}
\hline Characteristic & Outcome & $\begin{array}{l}\text { Number } \\
\text { respondents }\end{array}$ & of \\
\hline $\begin{array}{lll}\text { PrEP refers to antiretroviral medication used to prevent HIV } \\
\text { infection }\end{array}$ & Yes & 98 & 42 \\
& No & 35 & 15 \\
& I do not know & 92 & 40 \\
& Non-response & 7 & 3 \\
\hline HIV PrEP medication is given to HIV positive people & Yes & 27 & 12 \\
& No & 94 & 41 \\
& I do not know & 108 & 47 \\
& Non-response & 3 & 1 \\
\hline HIV PrEP medication is given to HIV negative people & Yes & 102 & 44 \\
& No & 23 & 10 \\
& I do not know & 104 & 45 \\
\hline
\end{tabular}




\begin{tabular}{llll}
\hline HIV PrEP is a lifelong medication & Yes & 29 & 13 \\
& No & 62 & 27 \\
& I do not know & 138 & 60 \\
& Non-response & 3 & 1 \\
\hline Does HIV PrEP have side effects? & Yes & 24 & 10 \\
& No & 52 & 22 \\
& I do not know & 154 & 66 \\
\hline Do you need to be tested before you receive HIV PrEP medication? & Non-response & 2 & 36 \\
& Yes & 83 & 16 \\
\hline
\end{tabular}

Table 3.4. Willingness to use PrEP

\begin{tabular}{|c|c|c|c|}
\hline Characteristic & Outcome & $\begin{array}{l}\text { Number of } \\
\text { respondents }\end{array}$ & Percentage \\
\hline \multirow[t]{3}{*}{ Would you use PrEP? } & Yes & 168 & 72 \\
\hline & No & 61 & 26 \\
\hline & Non-response & 3 & 2 \\
\hline \multirow[t]{4}{*}{ If not, why would you choose not to use PrEP? } & Fear of being stigmatised & 25 & 30.8 \\
\hline & Fear of possible side effects & 38 & 69.2 \\
\hline & Adherence and maintenance difficulty & 18 & 8 \\
\hline & Non-response & 151 & 65 \\
\hline \multirow[t]{5}{*}{$\begin{array}{l}\text { What influences your } \\
\text { willingness/unwillingness to use PrEP? }\end{array}$} & Culture & 36 & 16 \\
\hline & Religion & 22 & 10 \\
\hline & Peers & 89 & 38 \\
\hline & Lack of knowledge & 52 & 22 \\
\hline & Non-response & 33 & 14 \\
\hline \multirow[t]{3}{*}{ Have you ever taken PrEP? } & Yes & 10 & 4 \\
\hline & No & 214 & 92 \\
\hline & Non-response & 8 & 3 \\
\hline \multirow[t]{4}{*}{ What was the reason for taking PrEP? } & I do not always use condoms & 6 & 3 \\
\hline & I did not know my partner's HIV status & 19 & 8 \\
\hline & My partner has HIV & 15 & 7 \\
\hline & Non-response & 192 & 83 \\
\hline \multirow[t]{3}{*}{ Do you know anyone who has taken PrEP? } & Yes & 29 & 13 \\
\hline & No & 195 & 84 \\
\hline & Non-response & 8 & 3 \\
\hline \multirow[t]{4}{*}{ What was their reason for taking PrEP? } & $\begin{array}{l}\text { They wanted to take control of their } \\
\text { sexual health and PrEP would help them } \\
\text { to do this. }\end{array}$ & 18 & 8 \\
\hline & They do not always use condoms & 18 & 8 \\
\hline & Their partners has HIV & 19 & 8 \\
\hline & Non-response & 177 & 76 \\
\hline
\end{tabular}




\begin{tabular}{llll}
\hline $\begin{array}{l}\text { Do you know of anyone who has tried to } \\
\text { access PrEP services but was unable to? }\end{array}$ & Yes & 14 & 6 \\
& No & 210 & 91 \\
& Non-response & 8 & 3 \\
\hline
\end{tabular}

\subsection{Chi-Square Tests of Association (Cross Tabulation)}

Table 3.5. Awareness, knowledge and willingness to use the HIV PrEP services, their use of PrEP and the gender and study faculty of the respondents

\begin{tabular}{|c|c|c|c|c|}
\hline Cross tabulation & Chi-square value $^{1}$ & $n^{2}$ & $D f^{3}$ & p-value \\
\hline Have you ever heard of HIV PrEP? * Faculty & 10.560 & 229 & 2 & $0.005 * *$ \\
\hline Is HIV PrEP provided free of charge in state health facilities? ${ }^{*}$ Gender & 7.146 & 226 & 2 & $0.028 * *$ \\
\hline Is HIV PrEP provided free of charge in state health facilities? $*$ Faculty & 22.240 & 226 & 4 & $<0.001 * *$ \\
\hline $\begin{array}{l}\text { HIV PrEP refers to the antiretroviral medication used to prevent HIV } \\
\text { infection * Faculty }\end{array}$ & $\begin{array}{l}4.966 \\
\text { (linear-by-linear) }\end{array}$ & 225 & 1 & $0.026^{* *}$ \\
\hline HIV PrEP medication is given to HIV positive people * Gender & 13.081 & 229 & 2 & $0.001 * *$ \\
\hline HIV PrEP medication is given to HIV positive people * Faculty & 25.071 & 229 & 4 & $<0.001 * *$ \\
\hline HIV PrEP medication is given to HIV negative people * Faculty & 12.905 & 229 & 4 & $0.012 * *$ \\
\hline HIV PrEP is a lifelong medication * Faculty & 28.479 & 229 & 4 & $<0.001 * *$ \\
\hline HIV PrEP has side effect * Faculty & $\begin{array}{l}4.185 \\
\text { (linear-by-linear) }\end{array}$ & 230 & 1 & $0.041 * *$ \\
\hline $\begin{array}{l}\text { Must an individual be tested before he/she may receive HIV PrEP } \\
\text { medication* Faculty }\end{array}$ & 13.351 & 222 & 4 & $0.010^{* *}$ \\
\hline Do you know anyone who has taken PrEP? $*$ Faculty & 7.479 & 224 & 2 & $0.024 * *$ \\
\hline $\begin{array}{l}\text { Do you know of anyone who has tried to access HIV PrEP services but was } \\
\text { unable to? * Gender }\end{array}$ & 6.025 & 224 & 1 & $0.014^{* *}$ \\
\hline
\end{tabular}

\footnotetext{
${ }^{1}$ Pearson chi-square value, unless stated otherwise.

${ }^{2}$ Sample size.

${ }^{3}$ Degrees of freedom.

** p-value is statistically significant at 0.05 level of significance.
}

The results presented in Table 3.5 showed that, in general, the variation in terms of the gender of the respondents and the faculty in which they were studying may be used to explain the variation in the outcome variables, namely, knowledge, awareness and willingness to use the HIV PrEP services.

\section{Have you ever heard of HIV PrEP? * Faculty}

The results in Table 3.5 suggest that there is a statistically significant ( $p$-value $=0.005$ ) association between "Have you ever heard of HIV PrEP" and the faculty in which the respondent is studying. The study found that the students from the School of Nursing $(72 \%)$ were almost twice (odds ratio $=1.7242$ ) as likely to have heard of the availability of the HIV PrEP services compared to the students from the Faculty of Education (42\%) and those from the Economics and Management Sciences Faculty (40\%).

\section{Is HIV PrEP provided free of charge in state health facilities? * Gender * Faculty}

The response to the question as to whether or not HIV PrEP services are provided at no cost by state health facilities was found to be associated statistically with both the gender of the respondent ( $\mathrm{p}$-value $=0.028$ ) and the study faculty ( $\mathrm{p}$-value $<0.001$ ). In other words, a female respondent $(42 \%)$ was more likely (odds ratio $=1.446$ times) to be aware that HIV PrEP services are provided for free at various health facilities as compared to a male respondent (29\%). Similarly, students from the School of Nursing were 2.45 times $(56 \%)$ more likely to know that PrEP services are provided free of charge at various health facilities compared to students from the Faculty of 
Economics and Management Sciences (23\%) and Faculty of Education 37\%. The odds ratio of the students from the Faculty of Education knowing that PrEP services are provided free of charge at various health facilities compared to students from the Faculty of Economics and Management Sciences was 1.60.

\section{HIV PrEP refers to antiretroviral medication that is used to prevent HIV infection * Faculty}

With regard to the respondents' knowledge of the purpose of HIV PrEP, a student from the School of Nursing (56\%) was 1.618 times more likely to be knowledgeable about HIV PrEP than a student from the Faculty of Economics and Management Sciences (35\%), whereas the odds ratio of the students from the Faculty of Education (45\%) knowing the purpose of HIV PrEP is 1.299 compare those from the School of Nursing.

\section{HIV PrEP is a medication which is given to HIV negative people * Faculty}

Concerning the statement referring to whether or not HIV PrEP is a medication which is given to HIV negative people, a student from the Faculty of Economics and Management Sciences (56\%) was almost 3 times more likely to answer "I do not know" than a student from the School of Nursing (19\%). On the other hand, Nursing students (63\%) were 1.6846 times more likely know that HIV PrEP is given to HIV negative people compared to students from the Faculties of Economics and Management Sciences (37\%) and Education (44\%).

\section{HIV PrEP medication is given to HIV positive people * Gender * Faculty}

The study found that female respondents $(51 \%)$ were 1.71 times more likely to know that HIV PrEP is not given to HIV positive people compared to male respondents (30\%). Similarly, the findings indicate that Nursing students (72\%) were twice as likely to know that HIV PrEP medication is not given to HIV positive people as students from the Faculties of Education (36\%) and Economics and Management Sciences (36\%).

\section{PrEP is a lifelong medication * Faculty}

Table 3.5 showed that Nursing students (59\%) were 4.6047 times more likely to know that HIV PrEP is not a lifelong medication compared to students from the Faculties of Economics and Management Sciences (13\%) and Education (26.8).

\section{HIV PrEP has side effects * Faculty}

It was found that nursing students (34\%) were 2.4056 times more likely to be knowledgeable about whether or not HIV PrEP has side effects than students from the Faculties of Economics and Management Sciences (14\%) and Education (24\%).

\section{An individual needs to be tested before he/she may receive HIV PrEP medication * Faculty}

It emerged that the Nursing students $(63 \%)$ were 2.4606 times more likely to know that an individual needs to be tested before he/she may receive HIV PrEP medication than students from the Faculties of Economics and Management Sciences (25\%) and Education (37\%).

\section{Do you know anyone who has taken HIV PrEP? * Faculty}

The study revealed that the Nursing students (25\%) were 4.386 times more likely to know people who had taken HIV PrEP compared to the students from the Faculties of Economics and Management Sciences (6\%) and Education (14\%).

\section{Do you know of anyone who has tried to access HIV PrEP services but was unable to? * Gender}

It emerged that the male respondents (11\%) were 4.2 times more likely to know people who had tried to access HIV PrEP services but had been unable to than the female students (3\%).

\section{Discussions}

Table 3.2 showed that although only $45 \%$ of the respondents reported that they had heard about the availability of HIV PrEP services, $57 \%$ of them did not know where to access these services.

The results of the study have demonstrated that $45 \%$ only of the respondents had heard of HIV PrEP. Similar results have been reported in other studies such as a study which was conducted in Durham, North Carolina about public awareness of HIV PrEP, and which found that there was a low overall awareness of HIV PrEP among the respondents (North Carolina HIV/STD Surveillance Unit, 2016). Low awareness of PrEP (44\%) has also been found in nine middle-income and low-income countries (Yi, Te, Pengpid \& Peltzer, 2018). However, the results of this study were in contrast to those of a study which was conducted in Australia. The latter study found that the level of HIV PrEP awareness was relatively high among the respondents because $23 \%$ of participants only had never heard of PrEP, 51\% had heard a little about HIV PrEP and 25\% had heard a lot about it (Holt, Lea, Kippax, Kolstee, Ellard, Velecky et al., 2018). The current study also discovered that there was a low level of awareness of 
HIV PrEP among students from the Faculty of Economics and Management Sciences (40\%), as well as the students from Faculty of Education (42\%) at the UNAM Rundu Campus. However, the level of HIV PrEP awareness was found not to be significant across gender. This finding differs from that of a study which was carried out in Nigeria which revealed that the awareness of HIV PrEP was higher among the male participants than the female participants (Ajayi, Adeniyi, \& Akpan, 2018). Clearly, an HIV PrEP awareness campaign is necessary to increase the students' awareness and to encourage the use of HIV PrEP among all demographics at risk of HIV.

It also emerged from the study that health facilities, at 34\%, were the most likely source of information for the few respondents who were revealed to be HIV PrEP aware. It is thus imperative that other sources of information do more in disseminating information on HIV PrEP. In Australia it was found that the most common sources of information with regard to PrEP awareness included the gay community media, Australian websites, friends, being of a certain age, having a university degree and being tested for HIV were all regarded as being sources of information (Holt et al., 2018). The majority of the respondents (57\%) did not know where to access HIV PrEP services and only a low proportion (35\%) of individuals knew that HIV PrEP is provided free of charge at state health facilities. These findings indicated that such these respondents were not well informed about HIV PrEP as a preventative measure against HIV infection. These results are similar to those of a study conducted in Nigeria which found that $10 \%$ only of the students who participated in the study knew where to obtain HIV PrEP and very few knew how much it cost (Ajayi, Adeniyi, \& Akpan, 2018. These findings highlight that even if students are willing to take PrEP, they may not do so because of a lack of information about where to obtain it and, in addition, they may think they are unable to afford it. It is, thus, important that people know that HIV PrEP may be obtained at all health facilities countrywide in Namibia and is free of charge to all HIV negative people who are at risk of contracting HIV. In addition, this study found that some individuals were not well informed that HIV PrEP medication may also be used as a primary measure for the prevention of HIV.

Although $45 \%$ of the respondents had heard of HIV PrEP, a fairly large proportion (41\%) of them did not know what HIV PrEP was, as 59\% only of the respondents who had heard of HIV PrEP knew what HIV PrEP was. This finding compares favorably with the results of a study conducted in Madrid on awareness, knowledge, use and willingness to use, as well as the need for, HIV PrEP, which revealed that only $33 \%$ of respondents knew correctly what HIV PrEP was (Iniesta et al., 2018). Moreover, the fact that little is also known about HIV PrEP in Brazil may be due to clinical, behavioural, social and structural factors (Magno, Dourado, Coats, Wilhite, Da Silva, Oni-Orisan, et al., 2019). However, this assertion is contrary to the results of a study which was conducted in Australia which found that the level of knowledge of HIV PrEP was moderate compared to awareness thereof, which was low (Holt, Lea, Kippax, Kolstee, Ellard, Velecky et al., 2018).

It emerged from this study that $42 \%$ only of the respondents who had heard of HIV PrEP knew that it is not a lifelong medication. It is important that people are informed that PrEP may be taken only during specific periods of high risk and not for the individual's entire life (MoHSS, 2017). A significant number (65\%) of the respondents also did not know that HIV PrEP has side effects. It is imperative that people know that individuals taking PrEP may experience some minor side effects such as nausea and that, in rare cases, HIV PrEP may impact adversely on bone mineral density and kidney functioning (Bak, Van Dam, \& Janssen, 2018).

This study also revealed that a reasonably large proportion of the respondents who had heard of PrEP (44\%) did not know that an individual needs to be tested for HIV before HIV PrEP is prescribed. In addition, the study found that the Nursing students were more knowledgeable about HIV PrEP compared to the students from the Faculties of Education and Economics and Management Sciences. The low level of knowledge on the part of these students may be attributed to the fact that very few information campaigns have been conducted by the Ministry of Health and Social Services and other health-related stakeholders in Namibia to inform the public about the PrEP strategy. In addition, the political and legal situation in this regard was still unclear at the time of the study.

The study found that, of the respondents who had heard of HIV PrEP, $88 \%$ reported that they would use HIV PrEP. This result is similar to that of the study conducted in Madrid during world gay which indicated a high (67\%) degree of willingness on the part of the HIV negative participants to take HIV PrEP (Iniesta et al., 2018). A study which was carried out in West African countries also found that $87 \%$ of participants were willing to use HIV PrEP, mainly as a result of the risk of HIV infection (Coulaud et al., 2018). However, this result is in contrast to the result obtained in a study conducted in China, which reported that $36 \%$ only of the participants expressed a willingness to use HIV PrEP (Lorenz, 2019). The study in China concluded that only those who exhibited greater HIV testing behaviours and who were more engaged in decisions in respect of condom use were more likely to be willing to use HIV PrEP (Lorenz, 2019) as compared to their counterparts. A low level of willingness (39\%) to use HIV PrEP was also revealed in a study conducted in Malaysia (Lim et al., 2017). 
The results of this study found that $69 \%$ of the respondents were not prepared to use HIV PrEP because of their fear of possible side effects, while $31 \%$ feared being stigmatized. The level of willingness to use HIV PrEP may also be influenced by peer pressure. Similarly, it has been found in Asian countries that unwillingness to use HIV PrEP is caused by a lack of confidence in the efficacy of HIV PrEP, fear of side effects, adherence requirements, stigma and cost (Yi, Te, Pengpid, \& Peltzer, 2018). It would appear that, in Brazil, the unwillingness to use HIV PrEP was caused by clinical, behavioural, social and structural factors, including concerns about its efficacy and side effects, as well as the stigma associated with its use (Magno et al., 2019). In a study conducted in New York, some of the respondents were willing to use HIV PrEP but were unable to access it, while some of the respondents who had access to HIV PrEP had not discussed it with the health service providers (Wick, 2017).

The study found that $4 \%$ only of the respondents reported that they had taken PrEP, with $3 \%$ of them citing the inconsistent use of condoms during sexual intercourse as a reason for this. In addition, $8 \%$ indicated that they had taken HIV PrEP because they did not know their partners' HIV status. This result indicates a low use of PrEP among students at the University of Namibia. A low use of HIV PrEP was also observed in Germany, in Washington, and in New York (Ishiekwene, Powell-Thomas, Ghitan, Basti-Kuhn, Chapnick, \& Lin, 2018; Castel, 2018; Wick, 2017). Finally, 21\% of the respondents who reported that they had heard of HIV PrEP indicated that they knew someone who had taken HIV PrEP. This result indicated that the low use of HIV PrEP was not only among the students at UNAM but also among the general community in which the students lived.

With regard to the question as to whether or not the respondents knew anyone who had taken HIV PrEP, $13 \%$ only responded in the affirmative. This result was a further indication of the low use of HIV PrEP services within the respective community in general and not only among the respondents. Approximately $8 \%$ of the respondents mentioned that the people whom they knew were taking PrEP were doing so because they wanted to take control of their sexual health, while $8 \%$ were taking HIV PrEP because they did not always use condoms during sexual intercourse with their partners. The results of the study further indicated that $6 \%$ only of the respondents reported that they knew of someone who had tried to access HIV PrEP services but had been unable to do so.

The study included only small sample size which may not be representative of all students across the whole campuses. The rate of PrEP awareness, knowledge, willingness to use observed in this sample may therefore not be generalized outside this study. Concerning the research instrument, the questionnaire contained close ended questions. By implication, this meant limited response by respondents. Additionally, discussing sexual related topic is considered a taboo in African context; therefore, although the respondents were anonymous, there might have been information bias because some students were hesitant to report on sensitive information regarding the issues. Furthermore, the researcher noted that some questions were not answered in spite of clear instructions which were given. On a negative note, according to our knowledge there is limited literature in Sub-Sahara Africa and in African setting in general as the use of PrEP is new. Regarding the strength of this study, the concept of PrEP and HIV self-testing is very new to most African countries hence the significance of the results of the study will go a long way in creating awareness and promote the use of PrEP among first year students at UNAM Rundu Campus.

\section{Conclusion}

PrEP is an essential component of HIV combination prevention. This study has brought a broad picture of PrEP awareness, knowledge, willingness and use. There is low level of awareness, knowledge and use of PrEP. The study finding suggests that Knowledge regarding HIV PrEP existence is only high among nursing students. The low rate of awareness observed in this study highlighted an urgent need for expanded PrEP outreach to increase utilization among individuals at risk of acquiring HIV infection. Furthermore, concerted efforts should be continued among health care providers to promote interest and ensure equal access to this potentially lifesaving HIV prevention strategy. Moreover, every Namibian should play their part in achieving the sustainable development goal and make every effort toward ending the HIV pandemic by the year 2030. This study further revealed that there is significant interest in PrEP among students mainly because they want to take control over their sexual health and PrEP would help them to do so.

\section{Acknowledgements}

We would like to thank the UNAM and MoHSS research committees for granting permission to conduct the study. We would also like to thank all the respondents who took time to participate in this study. The study would not have been possible without their participation.

\section{Competing Interests Statement}

The authors declare that there are no competing or potential conflicts of interest. 


\section{References}

Ahouada, C., Diabaté, S., Gning, N. N., Hessou, S., Batona, G., Guédou, F. A., .. \& Alary, M. (2020). Acceptability of pre-exposure prophylaxis (PrEP) among men who have sex with men (MSM) in Benin: a qualitative study. AIDS care, 32(2), 242-248.

Ajayi, A. I., Ismail, K. O., Adeniyi, O. V., \& Akpan, W. (2018). Awareness and use of pre-exposure and postexposure prophylaxes among Nigerian university students: Findings from a cross-sectional survey. Medicine, 97(36). https://doi.org/10.1097/MD.0000000000012226

Bekker, L. G., Rebe, K., Venter, F., Maartens, G., Moorhouse, M., Conradie, F., ... \& Eakles, R. (2016). Southern African guidelines on the safe use of pre-exposure prophylaxis in persons at risk of acquiring HIV-1 infection. Southern African Journal of HIV Medicine, 17(1). https://doi.org/10.4102/sajhivmed.v17i1.455

Castel, A. D. (2018). Assessing PrEP knowledge, attitudes and potential uptake among adolescent and young adults at high risk of HIV in Washington. 8th International Conference on HIV Treatment and Prevention Adherence. Retrieved from https://www.iapac.org

Centre for Disease Control. (2018). HIV/AIDS. Retrieved from https://www.cdc.gov/hiv/basics/prep.html

Coulaud, P. J., Sagaon-Teyssier, L., M'madi Mrenda, B., Maradan, G., Mora, M., Bourrelly, M., ... \& Dagnra, C. A. Y. (2018). Interest in HIV pre-exposure prophylaxis in men who have sex with men in West Africa (Coh MSM ANRS 12324-Expertise France). Tropical Medicine \& International Health, 23(10), 1084-1091. https://doi.org/10.1111/tmi.13129

Holt, M., Lea, T., Kippax, S., Kolstee, J., Ellard, J., Velecky, M., ... \& de Wit, J. (2016). Awareness and knowledge of HIV pre-exposure prophylaxis among Australian gay and bisexual men: results of a national, online survey. Sexual Health, 13(4), 359-365.

Iniesta, C., Álvarez-del Arco, D., García-Sousa, L. M., Alejos, B., Díaz, A., Sanz, N., ... \& Del Amo, J. (2018). Awareness, knowledge, use, willingness to use and need of Pre-Exposure Prophylaxis (PrEP) during World Gay Pride 2017. PloS one, 13(10), e0204738. https://doi.org/10.1371/journal.pone.0204738

IntraHealth. (2019). PrEP and health worker training are protecting more Namibian girls from HIV. Retrieved from https://wwwintrahealth.org/news/prep-and-health-worker-training-are-protecting-more-namibian-girlshiv?language $=$ en

Ishiekwene, C., Thomas-Powell, S., Ghitan, M., Kuhn-Basti, M., Chapnick, E., \& Lin, Y. S. (2018). Evaluation of the awareness, knowledge and use of pre-exposure prophylaxis (PrEP) among the serodiscordant partners of HIV infected individuals on ART in an urban HIV clinic. Cogent Medicine, 5(1), 1475124. http://doi.org/10.1080/2331205x.2018.1475124

Lim, S. H., Mburu, G., Bourne, A., Pang, J., Wickersham, J. A., Wei, C. K. T., ... \& Azwa, I. (2017). Willingness to use pre-exposure prophylaxis for HIV prevention among men who have sex with men in Malaysia: Findings from an online survey. PloS one, 12(9), e0182838.

Lorenz, J. (2019). Raising PrEP awareness could improve use among female sex workers in China. Retrieved from https://www.contagionlive.com/news/raising-prep-awareness-could-improve-use-among-female-sexworkers-in-china

Magno, L., Dourado, I., Sutten Coats, C., Wilhite, D., da Silva, L. A. V., Oni-Orisan, O., ... \& Nunn, A. (2019). Knowledge and willingness to use pre-exposure prophylaxis among men who have sex with men in Northeastern Brazil. Global public health, 14(8), 1098-1111. https://doi.org/10.1080/17441692.2019.1571090

Ministry of Health and Social Services. (2017). National guidelines for antiretroviral therapy. Windhoek: MoHSS

Ministry of Health and Social Services. (2017). National Strategic Framework for HIV and AIDS response in Namibia 2017/18 to 2021/22. Directorate of Special Programmes

Namhindo, E. N., Mei, F., Cao, R., Lai, S., Dai, Y., Lai, H., ... \& Wang, J. (2018). PrEP: AIDS-Free Hope in Namibia. International Journal of Biology, 10(1). https://doi.org/10.5539/ijb.v10n1p13

North Carolina HIV/STD Surveillance Unit. (2016). Public awareness of HIV PrEP in Durham, North Carolina. Medical Journal. https://doi.org/10.18043/ncm.80.1.7

PEPFAR Media Information Session. (2017). HIV/AIDS in Namibia: Fast facts. May 19, $2017 ; 2$. 
PrEp watch. (2019). A snapshot of PrEp scale-up, registration and resources for Namibia. Retrieved from https://www.prepwatch.org/counter

The Society for Family Health Namibia. (2016). Pre-exposure prophylaxis, an additional prevention tool for HIV. Retrieved from https://www.google.com/url?sa=t\&source=web\&rct=j\&url

Tobias, N. (2018). PrEP is not a cure for HIV. Retrieved from https://shf.org.na/?p=291

UNAIDS. (2018). Global HIV \& AIDS statistics factsheet. Retrieved from http://www.unsaids.org/en/resources/fact-sheet

Wick, J. Y. (2017). HIV PrEP: Increasing willingness and intent to engage. Journal of Acquired Immune Deficiency Syndrome, 74(3), 285-295. https://doi.org/10.1097/QAI.0000000000001251

World Health Organisation. (2017). HIV/AIDS. Retrieved from www.who.int/mediacentre/factsheet/fs360/en/

Yi, S., Te, V., Pengpid, S., \& Peltzer, K. (2018). Social and behavioural factors associated with risky sexual behaviours among university students in nine ASEAN countries: a multi-country cross-sectional study. SAHARA-J: Journal of Social Aspects of HIV/AIDS, 15(1), 71-79. https://doi.org/10.1080/17290376.2018.1503967

\section{Copyrights}

Copyright for this article is retained by the author(s), with first publication rights granted to the journal.

This is an open-access article distributed under the terms and conditions of the Creative Commons Attribution license (http://creativecommons.org/licenses/by/4.0/). 